\title{
Incidence of third root in mandibular permanent first molar: An endodontic challenge
}

\author{
Ali M Rashid \\ BDS, MSc (Assist Lect)
}

Abdul-Haq A Suliman BDS, MS, MS, PhD (Prof)

\author{
Department of Conservative Dentistry \\ College of Dentistry, University of Mosul
}

\begin{abstract}
Aim: To investigate the incidence and the morphology of third root for the mandibular permanent first molars from indigenous Iraqi population and their significance in the successful of endodontic treatment. Materials and Methods: A clinical, radiographical prospective evaluation of first mandibular permanent molar teeth $(n=788)$ and laboratory analysis of 695 extracted first mandibular permanent molars collected from University Mosul, College of Dentistry, Department of Conservative Dentistry and private dental clinic were collected and examined. All the clinical cases treated as third root present, unless otherwise both $90^{\circ}, 20^{\circ}$ mesial radiographical shift and trapezoidal access opening excluded the presence of this macrostructure. The third root was classified in three groups on the basis of the curve of the root/root canal according to Ribeiro and Consolaro (1997). Chi-square was used to determine the significance between both genders, whereas descriptive statistics was used to describe the result of observations. Results: Upon clinical and laboratory observation of total 1483 first mandibular permanent molars, 121 (8.1\%) exhibited radix entomolaris (RE), 17 (14\%) were classified as type I (straight root/root canal), 33 (27.2\%) as type II (an initially curved entrance and the continuation as a straight root/root canals) and $71(58.6 \%$ ) as type III (an initial curve in the coronal third of the root canal and a second buccally orientated curve starting from the middle to apical third). Statistical analysis with Chi-square indicated no significant differences between both genders regarding the occurrence of RE. In all cases, RE occurred bilaterally. Out of 71 teeth attended for clinic, $87.3 \%$ teeth required retreatment, while the apparent reason of extraction for $86 \%$ of 50 collected extracted teeth with RE seemed failure of endodontic treatment and the cleaning and obturation confined to the mesial and distal canals only. In all cases, the orifice of the RE was located distolingual from the main canal in the distal root. Conclusion: Clinicians should be aware of this unusual root morphology in mandibular first molars. Radiographs exposed at two different horizontal angles are needed to identify this additional root. The access cavity must be modified in a distolingual direction in order to visualize and treat the RE; this results in a trapezoidal access cavity.
\end{abstract}

Key Words: Anatomical variations, endodontic treatment, radix entomolaris.

Rashid AM, Suliman AA. Incidence of third root in mandibular permanent first molar: An endodontic challenge. Al-Rafidain Dent J. 2006; 6(2): 194-198.

Received: 31/8/2006 Sent to Referees: 19/9/2006

Accepted for Publication: 16/10/2006

\section{INTRODUCTION}

The morphological knowledge of root canals is indispensable and improves the operator's ability to locate and trace a root canal to its termination, therapy increasing the degree of successful treatment. ${ }^{(1,2)}$

Mandibular first molar is the earliest permanent posterior tooth to erupt. It see$\mathrm{ms}$ to be the most frequently in need of endodontic treatment. It usually has two roots (mesial and distal), but occasionally three, with a supernumerary distolingual root. The majority of Caucasian first molars are two-rooted with two mesial and one distal canal. $^{(3,4)}$ The major variant in this tooth type is the presence of an additional third root, a supernumerary root which can be found lingually. This macrostructure, which is first mentioned in the literature by Carabelli (1844), is called radix entomolaris (RE). ${ }^{(5)}$ In European populations, it has been reported that a separate RE is present in the mandibular first molar with a maximum frequency of $3.4-4.2 \% .^{(2,6-10)}$ In African populations (Bantu, Bushmen, Senegalese) a maximum of $3 \%$ is found. ${ }^{(11-13)}$ In Eurasian and Indian populations the frequency is less than $5 \% .{ }^{(14)}$ In populations wi- 
th Mongoloid traits, such as Chinese, Eskimo and American Indians, the RE occurs with a frequency of $5 \%$ to more than $40 \%{ }^{(7,9,14-28)}$ Other researchers ${ }^{(20,29,30)}$ suggested that certain traits such as the "three-rooted molar" had a high degree of genetic penetrance as its dominance was reflected in the fact that pure Eskimo and Eskimo/Caucasian mixes had similar prevalence of the trait.

The aim of the present study was to investigate the incidence and the morphology of third root for the first mandibular permanent molars from indigenous Iraqi population and their significance in the successful of endodontic treatment.

\section{MATERIALS AND METHODS}

\section{Clinical Observation:}

A clinical and radiographic prospective evaluation was made for first mandibular permanent molars $(n=788)$ schedule for root canal treatment (including both for primary endodontic treatment and retreatment) were examined in the Department of Conservative Dentistry, College of Dentistry, University of Mosul, and private endodontic clinic in the same City. All the clinical cases treated as third root present, unless otherwise both $90^{\circ}, 20^{\circ}$ mesial radiographical shift and trapezoidal access opening excluded the presence of this macrostructure. The shortest side of trapezoid access opening is to the distal aspect, and the mesial side is slightly longer. The buccal and lingual sides are of approximately the same length and taper toward each other distally.

Those having third distoligual root were detected and counted using radiographic and clinical examination. Two preoperative radiographs were taken (AGFA Dentus, dental Dorngon, Germany), one a $90^{\circ}$ angulations to the tooth in a buccolingual direction and the other at a mesial angle of approximately $20^{\circ}$, to allow better visualization of the buccolingual anatomy. The radiographs were examined on a viewer using a peripheral block and a $\times 6$ aspheric magnifying lens. Another $20^{\circ}$ mesial shift intra-operative radiographs were taken with Flexofile ISO 10 (Dentsply Maillefer, Ballaigues, Switzerland) in the canal to confirm canal configuration.

\section{Laboratory Analysis:}

Six-hundreds and ninety five extracted first mandibular permanent molars from the Iraqi population were collected to be investigated in the laboratory. The teeth with three roots were isolated and their percentage to the all sample was counted and their third root was classified. About 8 teeth showed an orifice of canal indicating the fracture of this root upon the extraction. So, the record included only the incidence of occurrence of RE.

\section{Classification of Root Canal Anatomy:}

Based on the external root morphology and scouting of root canals of all the $\mathrm{RE}$ could be classified in three groups (Figure). This classification is based on a classification proposed by Ribeiro and Consolaro: ${ }^{(28)}$

- Type I refers to a straight root/root canal.

- Type II refers to an initially curved entrance and the continuation as a straight root/root canals.

- Type III refers to an initial curve in the coronal third of the root canal and a second buccally orientated curve starting from the middle to apical third.

Statistical analysis was done using Statistical Package for Social Sciences (SPSS) for Windows Version 11 Chi-square test was used to determine the significance between both genders, whereas descriptive statistics was used to describe the result of observations.

\section{RESULTS}

Upon clinical and laboratory observation of total 1483 first mandibular permanent molars, 121 (8.1\%) exhibited RE, 17 (14\%) were classified as type I, 33 (27.2\%) as type II and 71 (58.6 \%) as type III (Figure Table).

Although 63 (52\%) males exhibited RE compared with 58 (47.9\%) females, statistical analysis with Chi-square indicated no significant differences between both genders. In all cases, the occurrence of RE was bilaterally. Out of 71 teeth with RE attended for clinic, 62 teeth (87.3\%) teeth required retreatment due to failure of primary endodontic treatment mainly to inability of the operators to identify and treat RE; 
while the apparent reason for extraction of $43(86 \%)$ of 50 collected extracted teeth with RE seemed failure of endodontic trea- tment and the cleaning and obturation confined to the mesial and distal canals only.

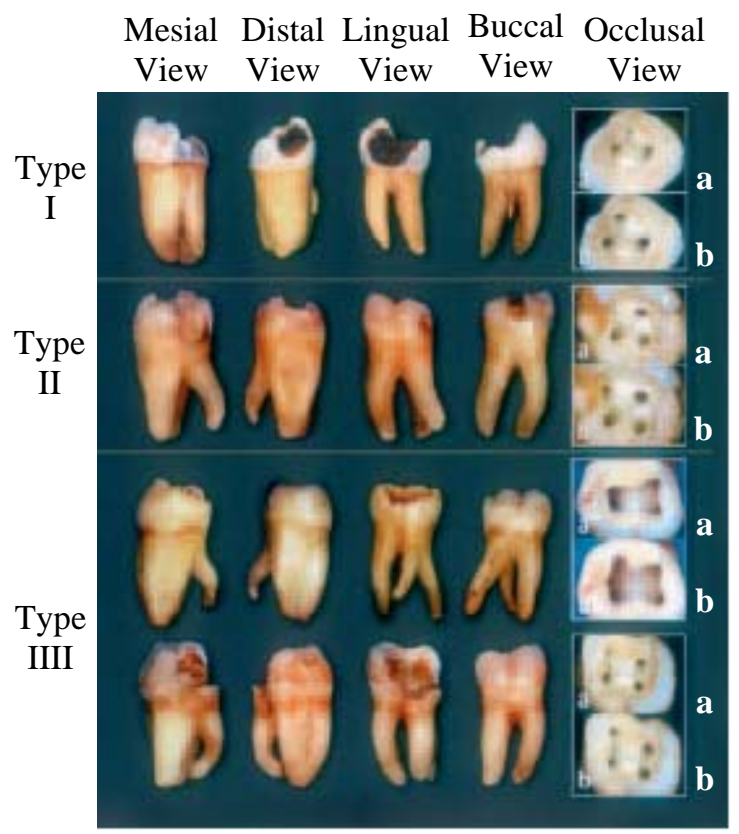

a: Original opening cavity; b: Modification of the opening cavity for the localization of the orifices of the radix entomolaris (RE) and the preparation of the root canal.

Type I: A straight root/root canal; Type II: Initially curved entrance of the root canal and the continuation as a straight root/root canals; Type III: Initial curve in the coronal third of the root canal and a second buccally orientated curve starting from the middle third. The RE may also have a pronounced curve in the apical part of the root (in one of the root filled teeth of this case study this was a 90 -buccal curve).

Figure: Classification of the extracted mandibular first molars with a radix entomolaris and occlusal view on the pulp chamber and root canal orifices

Table: Numbers and percentage of root and root types of radix entomolaris

\begin{tabular}{cccccc}
\hline & No. & $\begin{array}{c}\text { No. (\%) of } \\
\text { RE }\end{array}$ & $\begin{array}{c}\text { No. (\%) of } \\
\text { RE Type I }\end{array}$ & $\begin{array}{c}\text { No. (\%) of } \\
\text { RE Type II }\end{array}$ & $\begin{array}{c}\text { No. (\%) of } \\
\text { RE Type III }\end{array}$ \\
\hline $\begin{array}{c}\text { Clinical } \\
\text { Observation } \\
\text { In vitro }\end{array}$ & 788 & 63 & & & \\
$\begin{array}{c}\text { Analysis } \\
\text { Total }\end{array}$ & 695 & 58 & $17(14 \%)$ & $33(27.2 \%)$ & $71(58.6 \%)$ \\
\hline
\end{tabular}

RE: Radix entomolaris.

In all cases, the orifice of the RE was located distolingually from the main canal in the distal root. The position was also characteristic for the root filled molars examined in situ. Only the trapezoidal access opening and tube shift radiographic technique were valuable in the locating of RE.

\section{DISSCUSION}

Morpho-anatomic changes in teeth may be divided according to the site of their occurrence; i.e., tooth crown, roots and root canals. Third root anomalies with close similarity inherited by different etiology. These anomalies may develop during tooth bud morpho-differentiation as a result of a developmental aberration of both the ectoderm and mesoderm. ${ }^{(31)}$ Its severity depends on the formation stage of the involved teeth.

One of the main reason for failure of root canal treatment in molars is because the clinician has not removed all the pulp tissue and microorganisms from the root canal system. ${ }^{(32)}$ This fact will be reflected clearly by the high percent of root canal failure. This lead to either retreatment (87.3\%) or extraction (86\%). Among such unusual anatomy in this study, therefore, knowing the variations in root canal morp- 
hology is helpful in predicting the presence of an "extra" canal and/or root.

Curzon $^{(20)}$ suggested that certain traits such as the "three-rooted molar" had a high degree of genetic penetrance as its dominance was reflected in the fact that pure Eskimo and Eskimo/Caucasian mixes had similar prevalence of the trait. This fact reflected by this study, as there was no significance between both genders as well as it occurred bilaterally, so the genetic markers is the role.

The high percent of type III canals (58.6\%) will added more difficulties of root canal cleaning, shaping and obturation, because a second buccally orientated curve starting from the middle to apical third of the canal provide misleading radiograph related to lake of third dimension, especially with regarding of working length determination.

These variations in distal root anatomy may be identified through careful reading of angled radiographs. Slowley ${ }^{(29)}$ has demonstrated how difficult it is to detect extra roots, let alone extra canals. On the contrary, completing a thorough radiographic study of the involved tooth with exposure from three different horizontal projections, the standard buccal-to-lingual projection, 20 from the mesial, and 20 from the distal reveals the basic information regarding the anatomy of the tooth in order to perform endodontic treatment. ${ }^{(30)}$

Anatomical variations of mandibular molars are documented in the literature. Nonetheless, variations of the anatomy of the root canal system in molars are not appreciated by a great number of general practitioners. $^{(33,34)}$ This study concentrated on the value of misinterpretation of radiograph and their effect on the success of endodontic treatment. It was believed that radiographic interpretation, like diagnosis itself, is part science and part art and intuition.

The operator should have no qualms about modification the access opening whenever they suspected about the additional root and cutting and down the distolingual portion of the tooth. Otherwise if the canal cannot be located and would be failed, so conservation of the tooth structure would be useless.

\section{CONCLUSIONS}

It is essential to anticipate and find all canals during molar root canal treatment. Proper angulation and interpretation of radiographs help to identify chamber and root anatomy. In the case of RE, the conventional triangular opening cavity must be modified to a trapezoidal form in order to better locate and access the distolingually located orifice of the additional root. Straight-line access, in this respect, has to be emphasized as the majority of the RE are curved.

\section{REFREENCES}

1. Skidmore AE, Bjorndahl AM. Root canal morphology of the human mandibular first molar. Oral Surg Oral Med Oral Pathol. 1971; 32: 778-784.

2. Schilder H, Sam W. The comparison of curved canal preparation in straight and curved root canal. Oral Surg Oral Med Oral Pathol. 1971; 32: 112-114.

3. Barker BCW, Parson KC, Mills PR, Williams GL. Anatomy of root canals. III. Permanent mandibular molars. Aust Dent J. 1974; 19: 403-413.

4. Vertucci FJ. Root canal anatomy of the human permanent teeth. Oral Surg Oral Med Oral Pathol. 1984; 58: 589-599.

5. Bolk L. The importance of endodontic in maxillary and mandibular molar canals. $J$ Canad Dent Assoc. 1994; 60: 527-532.

6. Taylor AE. Variations in the human tooth form as met within isolated teeth. $J$ Anat Physiol. 1899; 33: 268-272.

7. De Souza-Freitas JA, Lopes ES, CasatiAlvares L. Anatomic variations of lower first permanent molar roots in two ethnic groups. Oral Surg Oral Med Oral Pathol. 1971; 31: 274-278.

8. Curzon MEJ. Three-rooted mandibular permanent molars in English Caucasians. J Dent Res. 1973; 52: 181-183.

9. Ferraz J. Three rooted mandibular molars in patients of Mongolian, Caucasian and Negro origin. Braz Dent J. 1992; 3: 113117.

10. Steelman R. Incidence of an accessory distal root on mandibular first permanent molars in Hispanic children. J Dent Child. 1986; 53: 122-123.

11. Drennan MR. The dentition of the Bushmen tribe. Annals SAfr Museum. 1929; 24: 61-87. 
12. Shaw JCM. The Teeth, the Bony Palate and the Mandible in Bantu Races of South Africa. John Bale, Sons and Danielson. London, UK. 1931.

13. Sperber GH, Moreau JL. Study of the number of roots and canals in Senegalese first permanent mandibular molars. Int Electr J. 1998; 31: 117-122.

14. Tratman EK. Three-rooted lower molars in man and their racial distribution. $\mathrm{Br}$ Dent J. 1938; 64: 264-274.

15. Laband F. Two years' dental school work in British North Borneo: Relation of diet to dental caries among natives. $J$ Am Dent Assoc. 1941; 28: 992-998.

16. Pedersen PO. The East Greenland Eskimo dentition. Numerical variations and anatomy. Meddelelser Om Gronland. 1949; 142: 141-149.

17. Curzon MEJ, Curzon JA. Three-rooted mandibular molars in the Keewatin Eskimo. J Canad Dent Assoc. 1971; 37: 874878.

18. Somogyl-Csizmazia W, Simons AJ. Three-rooted mandibular first molars in Alberta Indian Children. J Canad Dent Assoc. 1971; 37: 105-106.

19. Turner CGII. Three-rooted mandibular first permanent molars and the question of American Indian origins. Am J Phys Anthropol. 1971; 34: 229-241.

20. Curzon MEJ. Miscegenation and the prevalence of three-rooted mandibular first molars in Baffin Eskimo. Community Dent Oral Epidemiol. 1974; 2: 130-131.

21. Hochstetter RL. Incidence of trifurcated mandibular first permanent molars in the population of Guam. J Dent Res. 1975; 54: 109-114.

22. Jones AW. The incidence of the threerooted lower first permanent molar in Malay people. Singapore Dent J. 1980; 5: 15-17.

23. Reichart PA, Metah D. Three-rooted permanent mandibular first molars in the Thai. Community Dent Oral Epidemiol.
1981; 9: 191-192.

24. Walker RT, Quackenbush LE. Three-rooted lower first permanent molars in Hong Kong Chinese. Br Dent J. 1985; 159: 298-299.

25. Walker RH. The root canals anatomy of mandibular first permanent molars in Southern Chinese population. Endod Dent Traumatol. 1988; 4: 19-22.

26. Yew SC, Chan K. A retrospective study of endodontically treated mandibular first molars in a Chinese population. $J$ Endod. 1993; 19: 471-473.

27. Gulabivala K, Aung TH, Alavi A, Ng YL. Root and canal morphology of Burmese mandibular molars. Int Endod $J$. 2001; 34: 359-370.

28. Ribeiro FC, Consolaro A. Importancia clinica y antropologica de la raiz distolingual en los molars inferiores permamentes. Endodoncia. 1997; 15: 72-78 (English Abstr).

29. Slowley RR. Radiographic aids in the detection of extra root canals. Oral Surg Oral Med Oral Pathol. 1974; 37: 762772.

30. Ingle JI, Heithersay GS, Hartwell GR. Endodontic diagnostic procedures. In: Ingle JI. Endodontics. $4^{\text {th }}$ ed. Lea and Febiger. Philadelphia. 2002; Pp: 123-127.

31. Grover PS, Lorton L Gemination and twinning in the permanent dentition. Oral Surg Oral Med Oral Pathol. 1985; 59: 313-318.

32. Cohen AS, Brown DC. Orofacial dental pain emergencies: Endodontic diagnoses and management. In: Cohen S, Burns RC (eds). Pathways of the Pulp. $8^{\text {th }}$ ed. CV Mosby Co. Boston. 2002; Pp: 31-75.

33. Slaus G, Bottenberg P. A survey of endodontic practice amongst Flemish dentists. Int Endod J. 2002; 35: 759-767.

34. Hommez GMG, Braem M, De Moor RJG. Root canal treatment performed by Flemish dentists. Part 1. Cleaning and shaping. Int Endod J. 2003; 36: 166-173. 